INEEL/EXT-2000-00479

June 2000

\title{
Remote Laser Diffraction PSD Analyzer
}

T. A. Batcheller

G. M. Huestis

S. M. Bolton 


\section{Remote Laser Diffraction PSD Analyzer}

T. A. Batcheller

G. M. Huestis

S. M. Bolton

Published June 2000

Idaho National Engineering and Environmental Laboratory High Level Waste Program

Prepared for the U.S. Department of Energy Under DOE Idaho Operations Office Contract DE-AC07-99ID13727 


\begin{abstract}
Particle size distribution (PSD) analysis of radioactive slurry samples was obtained using a modified "off-the-shelf" classical laser light scattering particle size analyzer. A Horiba Instruments Inc. Model LA-300 PSD analyzer, which has a 0.1 to 600 micron measurement range, was modified for remote application in a "hot cell" (gamma radiation) environment. The general details of the modifications to this analyzer are presented in this paper.

This technology provides rapid and simple PSD analysis, especially down in the fine and microscopic particle size regime. Particle size analysis of these radioactive slurries down in this smaller range was not achievable - making this technology far superior than the traditional methods used previously. Remote deployment and utilization of this technology is in an exploratory stage. The risk of malfunction in this radiation environment is countered by the gaining of this tremendously useful fundamental engineering data. Successful acquisition of this data, in conjunction with other characterization analyses, provides important information that can be used in the myriad of potential radioactive waste management alternatives.
\end{abstract}




\section{ACKNOWLEDGMENTS}

With the successful deployment of the modified Horiba LA-300 laser light scattering PSD analyzer in the RAL facility, the authors would like to take this opportunity to recognize the folks that supported this task. First, thanks to Mike Patterson, Arlin Olson and Ken Brewer for providing this opportunity and the space to accomplish this work. Mike Phippen provided the machine shop wizardry for the major modifications/fabrications. Earlen Wade improved the design and the quality of this unit with his creativity and immense experience. Carl Lundholm was a great resource for input on the remote aspects of this unit. Kudos to the remote operators/analysts at the RAL facility who assisted with this tasks; to the individuals at the CPP 663 Maintenance Shop who assisted; to the Remote Mockup folks at the Test Reactor Area; to Sharla Mickelsen, Lonnie Olson, and Patty Tullock for their assistance; to Julia Tripp and Nick Mann who first endeavored the "startup curve" on this task. Finally, thanks to Mr. Duncan Griffiths, and the rest of the folks at Horiba Instruments Inc. who provided technical support. 


\section{CONTENTS}

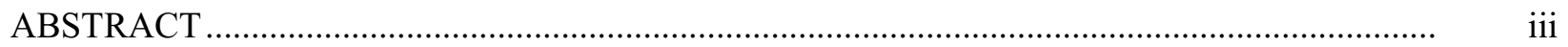

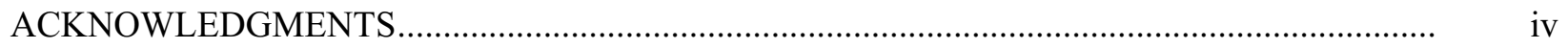

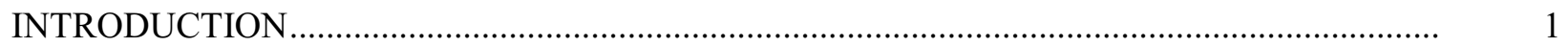

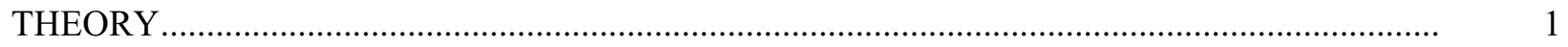

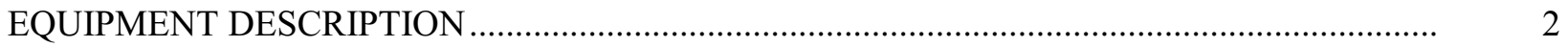

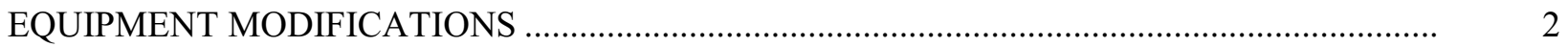

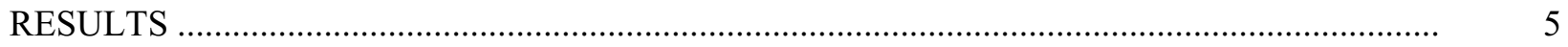

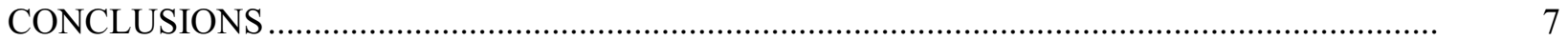

\section{FIGURES}

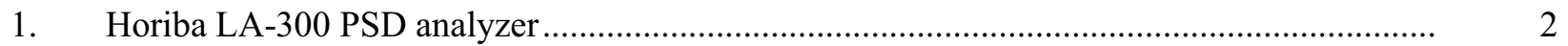

2. Horiba sheet metal chassis and cover box assembly ....................................................... 3

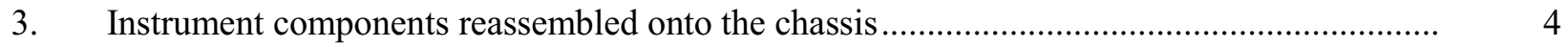

4. Modified sample circulation tubing in sample chamber .....................................................

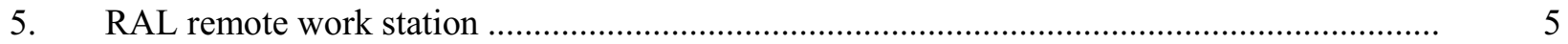

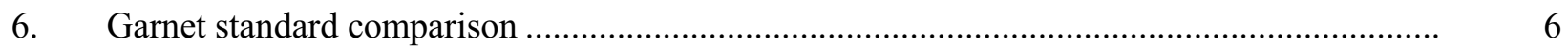

7. Overlay of tank farm vessel WM182 slurry PSD analyses................................................ 


\section{Remote Laser Diffraction PSD Analyzer INTRODUCTION}

In support of a radioactive slurry sampling and physical characterization task, a laser diffraction (classical light scattering) particle size analyzer was modified for remote particle size distribution (PSD) analysis in a Remote Analytical Laboratory (RAL) facility. The RAL is at the INTEC

(Idaho Nuclear Technology and Engineering Center) and is located on DOE's Idaho National Engineering and Environmental Laboratory site, east of Arco, Idaho. Spent nuclear fuel was previously reprocessed at the INTEC (formerly recognized as the Idaho Chemical Processing Plant) utilizing liquid-liquid extraction processes. The acidic, radioactive aqueous streams from these processes were transferred to stainless steel storage vessels in the INTEC Tank Farm area, where each vessel sits below grade, and is totally enclosed in a concrete vault. This radioactive liquid was subsequently transferred to a solidification process where a dry granular calcine material was formed (from the liquid). However, due to the liquid transfer piping configuration in the tank farm vessels, 100 percent of this liquid could not be retrieved. Consequently, a liquid "heel" remains at the bottom of an "emptied" vessel. The particle size distribution characterization of the solids in this remaining heel slurry, as well as solids suspended in the tank liquid, is the goal of this remote PSD analyzer task.

\section{THEORY}

For classical light scattering, the scattering angle and intensity of a monochromatic light source is dependent upon particle size. In general, larger particles diffract light less, and at a smaller angle (forward-angle). Smaller particles scatter light more, and at wider angles. The Mie theory of light scattering quantitatively describes the scattering phenomena with primarily the light source wavelength $\lambda$, and the scattering intensity and angle; for smaller particles, the ratio of the refractive index of the particle to that of the dispersing medium, and the imaginary component of the index may come into play. With the "marriage" of laser/optical semiconductor technology, numerical methods, and high speed microcomputers, solution of the Mie equation to obtain a rapid, accurate and reproducible benchtop particle size analysis for actual particle light scattering data is realized.

A typical classical light scattering PSD analyzer optical system is composed of four components: 1) a laser light source 2) a lens setup 3) a sample cell through which the laser beam is passed/aligned, and 3 ) an array of detectors at various angles to the sample cell. Particles are circulated through the sample cell and the monochromatic laser light diffraction/scatter pattern from the particles emanates from the cell. The lens setup, in conjunction with alignment of the laser, focuses undiffracted light to the center of the detector array. For a sample PSD analysis, the cumulative saturation of the scattered light on each detector is summed. Algorithms in the analyzer software use the corresponding detector angle and light saturation summation data to deconvolute the particle size distribution (within the analyzers limits) utilizing the Mie theory. 


\section{EQUIPMENT DESCRIPTION}

A Horiba Instruments Inc. Model LA-300 PSD analyzer, which has a 0.1 to 600 micron measurement range and weighs $55 \mathrm{lbs}$., was chosen for this PSD analysis task primarily because it satisfied a 12 inch wide RAL transfer tunnel dimension restriction - and because of its smaller "footprint". This classical light scattering technology provides rapid and simple PSD analysis, especially down in the fine and microscopic particle size regime. Particle size analysis of these radioactive slurries down in this smaller range was previously not achievable. This technology is therefore far superior than the traditional methods used before. The Horiba LA-300 optical bench system is comprised of: 1) a $650 \mathrm{~nm} \lambda$ laser diode light source with a converging lens, 2) a laser auto alignment unit which uses a movable mirror to align the beam, 3) a Tempax ${ }^{\circledR}$ glass sample cell, and 4) a 36-channel forward-angle ring detector and 6 individual wide-angle detectors. Because the spatial relationship of these components is critical, they are precisely mounted on a substantial metal base. The laser provides the monochromatic light and the lens condenses the beam. The beam is precisely aligned on the center of the ring detector by adjusting the mirror. The beam is now precisely aligned with the glass sample cell and all of the detectors. At this condition, each detector electrical signal level is "zeroed" for the summing of the light saturation in the ensuing sample analysis. Thus the optics have been aligned and the detectors/electronics have been baselined, and the analyzer is ready to perform an analysis. During all of these operations described thus far, a clean dispersant liquid, in this case water, is being circulated through the sample cell. Therefore the instrument has been baselined to the clean/blank water dispersant. Particles are now added to the circulating dispersant until the laser beam transmittance is reduced enough to establish an adequate diffraction/scatter pattern. The particle size distribution can now be determined/analyzed by the instrument.

\section{EQUIPMENT MODIFICATIONS}

Before this analyzer could be used in this remote application, several minor modifications to the Horiba analyzer were made. A list of the modifications that were done to the "off-the-shelf" analyzer follows along with some figures; the analyzer is shown in Figure 1:

- Design, fabricate, and assemble "ice chest" remote lifting handle.

- Blank off analyzer bench cooling fan air intake vents on bottom of analyzer chassis (in-cell nitric acid vapor effects mitigation).

- Coat exposed surfaces of sheet metal chassis with epoxy paint (in-cell acid vapor).

- Fabricate Teflon feet; fabricate Teflon spacer to fill gap at bottom front of analyzer.

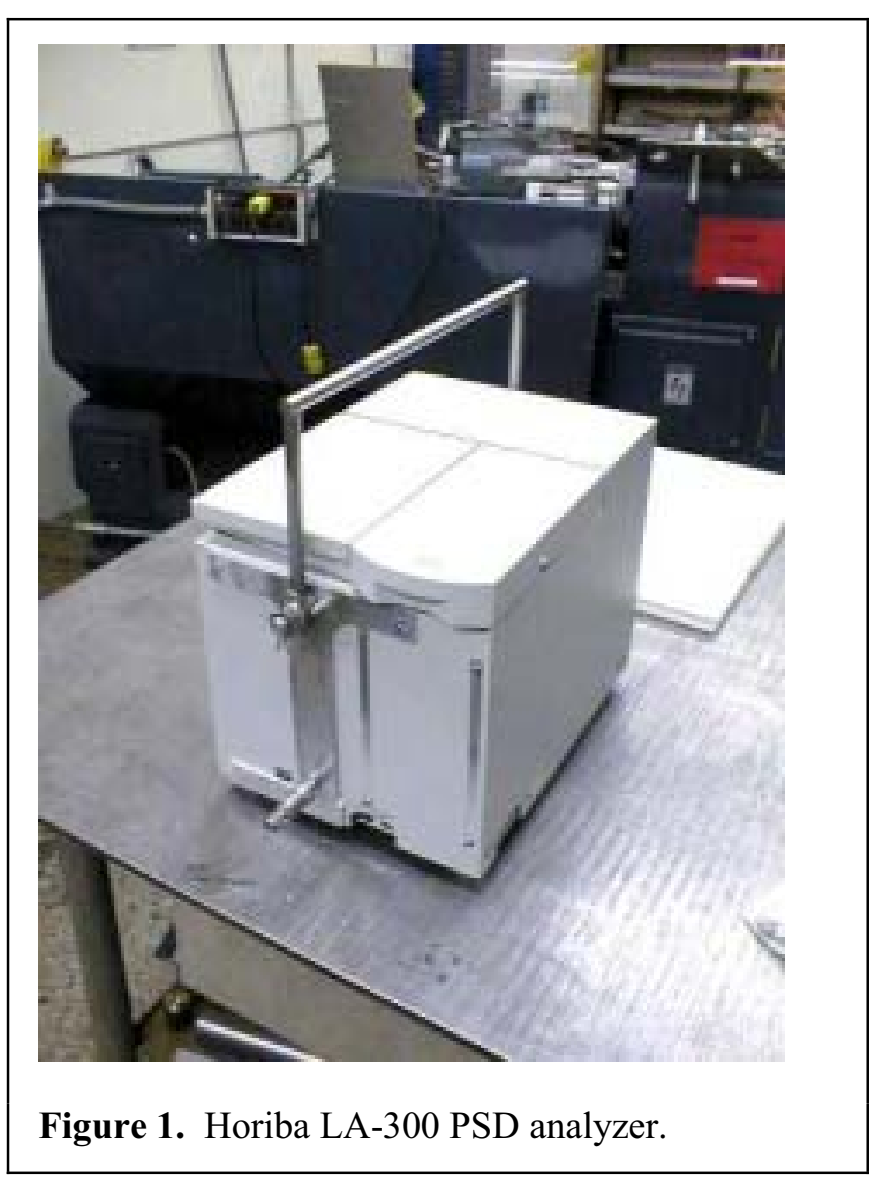


- Relocate sample drain block/outlet to front of analyzer; mount SS quick disconnects for fresh air purge line to front of analyzer; assemble remote drain lines.

- Replace existing sample pump drive EDPM O-ring with a Viton ${ }^{\circledR}$ O-ring.

- Replace silicone tubing with Teflon lined Viton tubing and custom bent SS tubing (to alleviate Teflon lining kinking in the Viton tubing).

- Replace sponge gasket between sample tank and mounting deck with Teflon gasket rope.

- Rewire/modify PC com link printed circuit board to accommodate a Lemo remote connector; Lemo

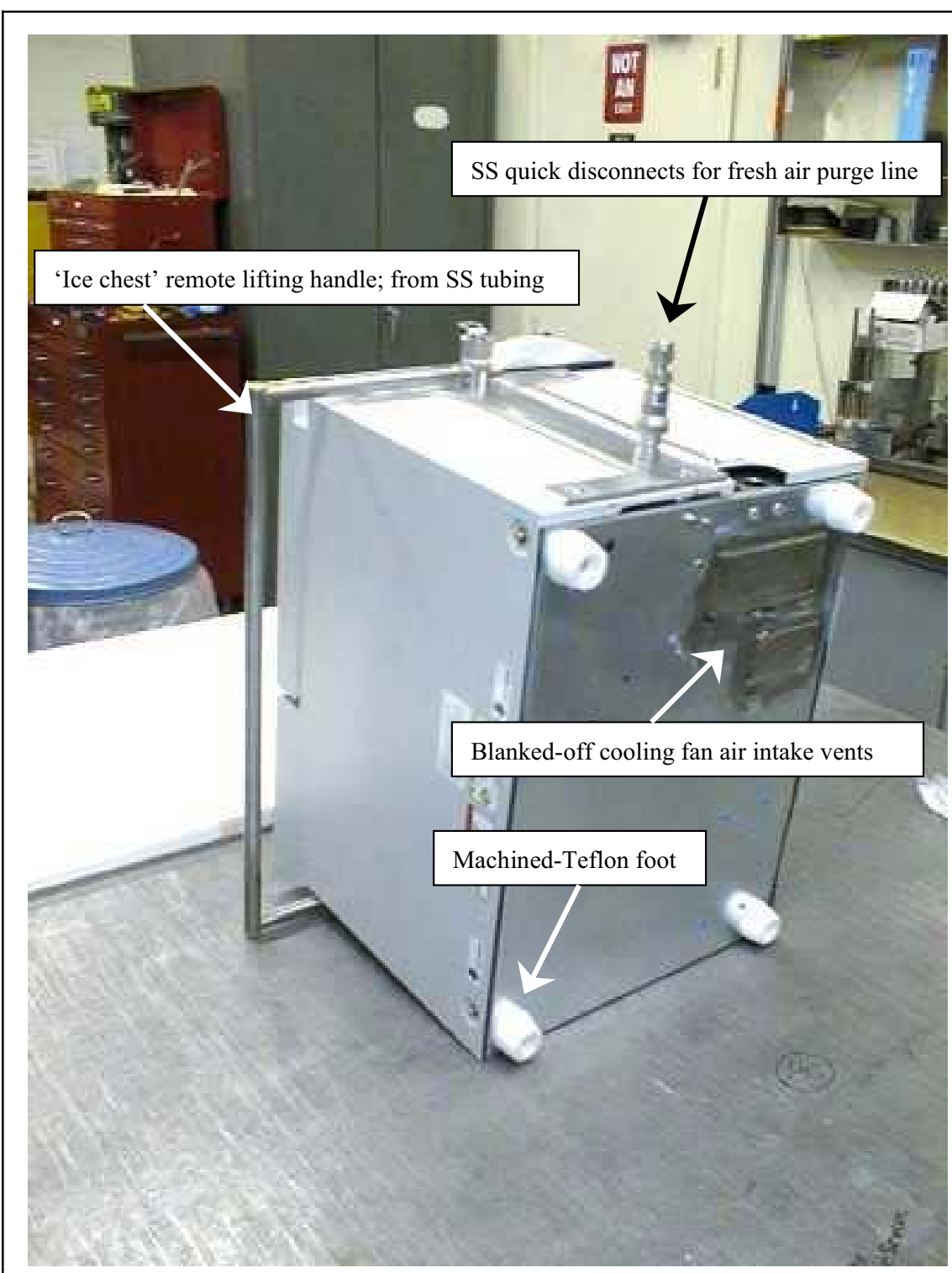

Figure 2. Horiba sheet metal chassis and cover box assembly. connector receptacle mounted in upper right-hand corner of the back of the unit.

These modifications are shown in Figures 2, 3 and 4. The Horiba analyzer is controlled with a personal computer via a serial link communication cable. For this remote application, two custom communication cables were made-up. The inside-cell cable has a Lemo connector plug on one end, and a special plug for the in-cell penetration receptacle on the other. The out-of-cell cable has a plug for the outside cell penetration receptacle on one end, and the standard PC connector on the other. 


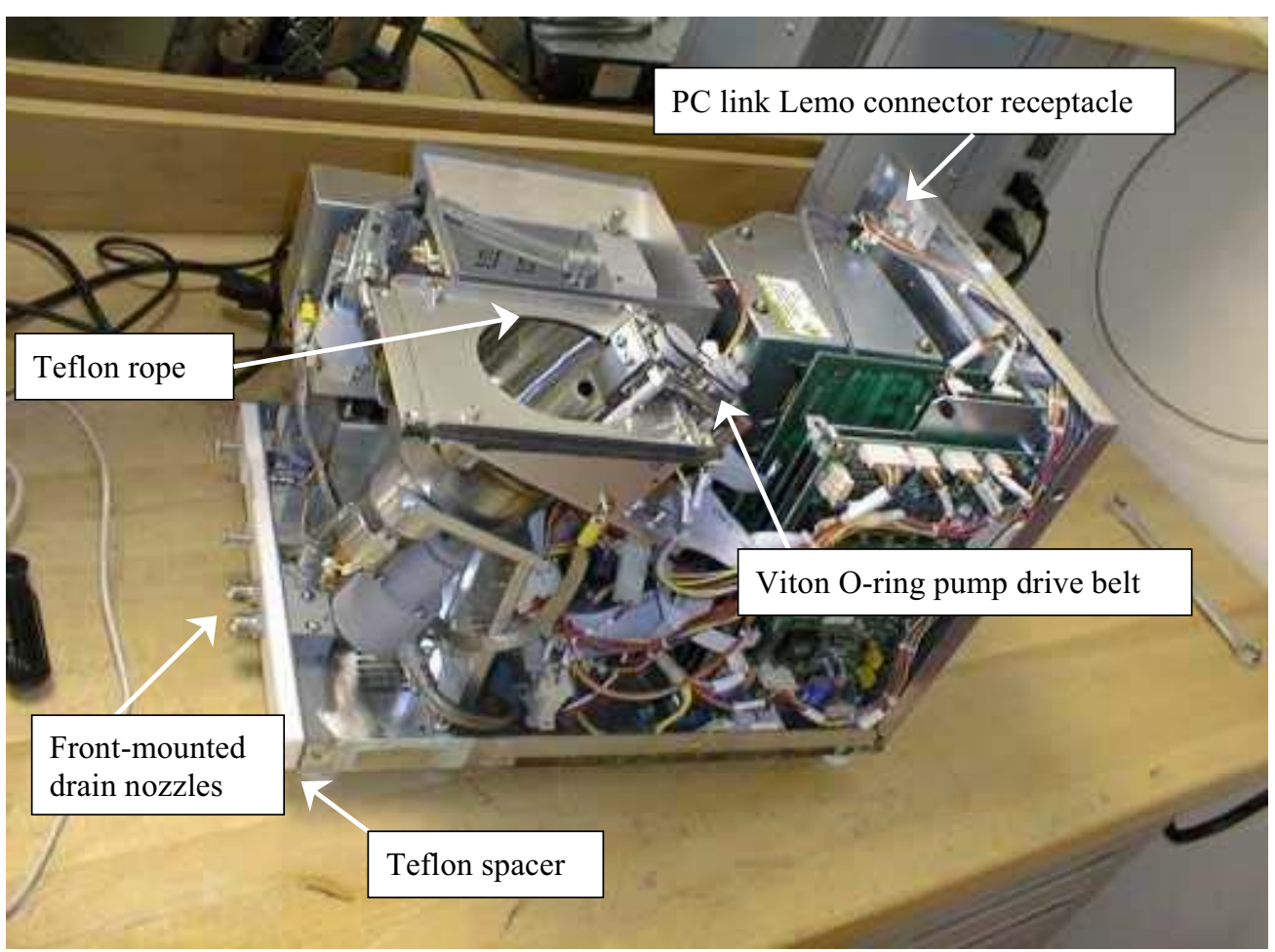

Figure 3. Instrument components reassembled onto the chassis.

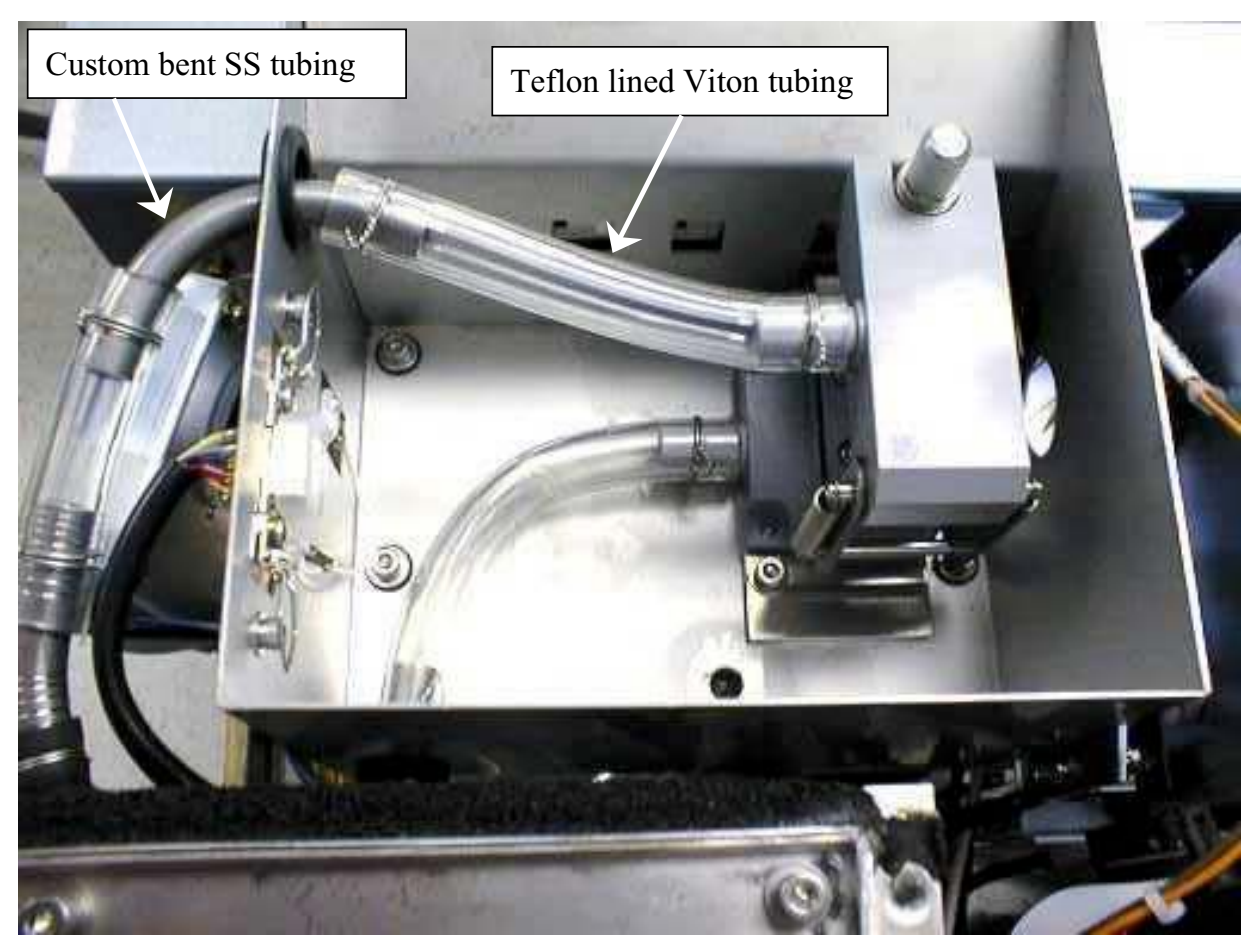

Figure 4. Detailed view of modified sample circulation tubing in the sample chamber. 


\section{RESULTS}

The modified unit was bench tested with standards and samples to validate that the instrument performed at the pre-modification level of analysis accuracy and repeatability. The instrument was then set-up at a remote mockup facility (non-radioactive area). Standard and sample PSD analyses were performed under simulated remote conditions; this was done to learn, practice, and demonstrate operator technique. Upon satisfactory completion of these items, the unit was assembled for the final time - and a bead of Fluorodyn ${ }^{\mathrm{TM}}$ Viton caulk was run all-way-round the gap at bottom of unit (gap between the heavier gauge sheet metal chassis and the lighter gauge box/cover; see Figure 2). The unit was ready for utilization in the RAL.

Deployment of the modified unit at the RAL was achieved in December 1999. The Horiba analyzer is located at a RAL workstation/window; this is shown in Figure 5. The operator performs work by looking through the lead glass shielding window. His hand motions in the handgrips are translated to the in-cell manipulators (see lower photograph in Figure 5). The concrete cell wall and shielding window mitigate the gamma radiation hazard.

Satisfactory remote operation and, accuracy and repeatability were demonstrated with an analysis of the $35 \mu \mathrm{m}$ modal garnet control standard which was used throughout this task; this is presented in Figure 6. This remote analysis is overlayed and compared with prior analyses of this standard. As can be seen in Figure 6, there is very good agreement between these PSD analyses.

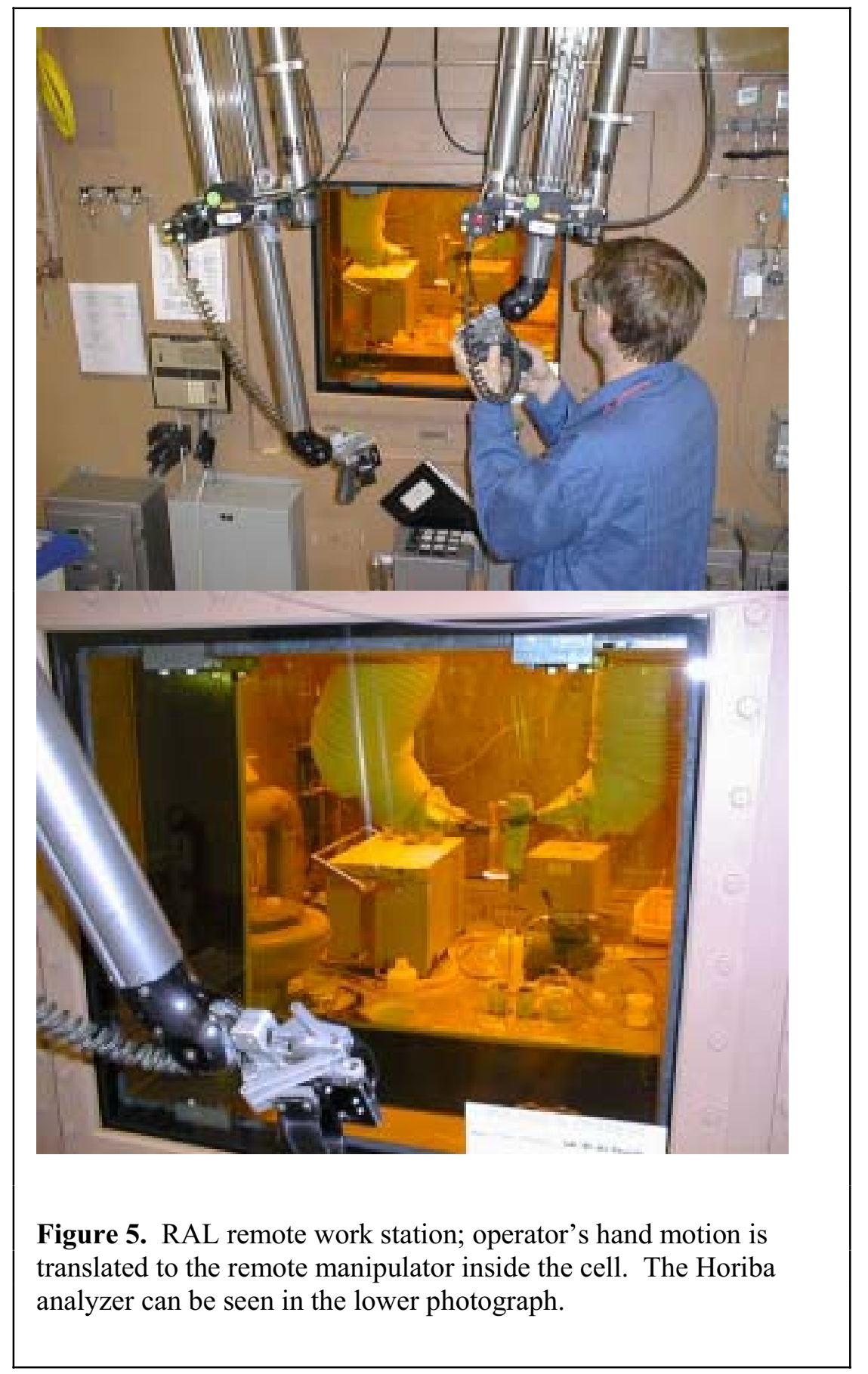




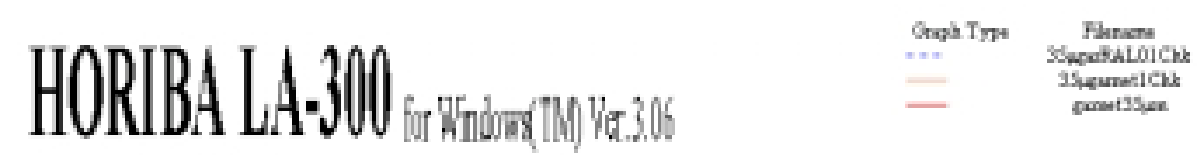

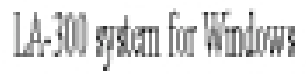
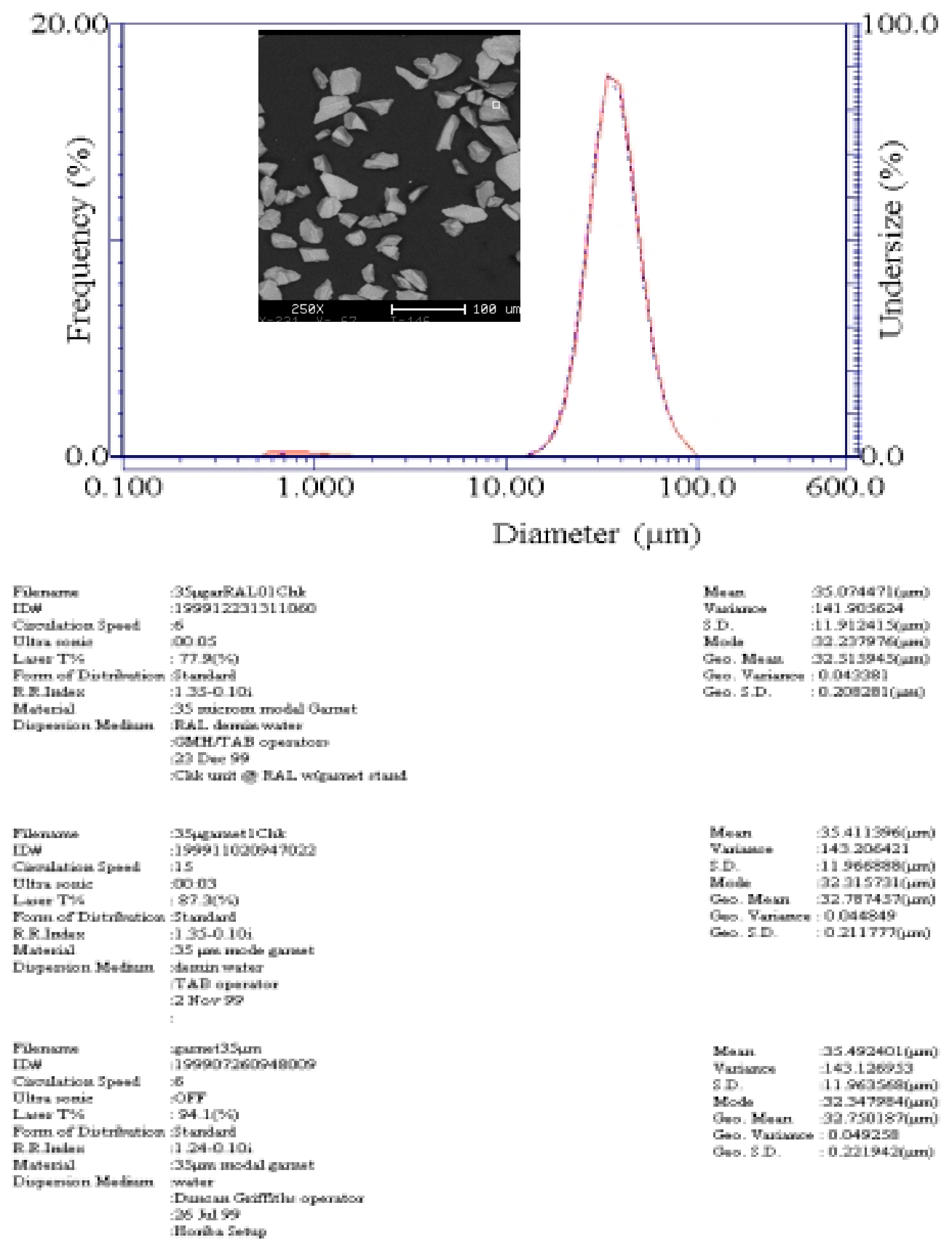

Figure 6. Garnet standard comparison; SEM photomicrograph insert of $35 \mu \mathrm{m}$ modal garnet standard material; sample $35 \mu$ garRAL01Chk was performed remotely at RAL; sample 35 $\mu$ garnet1Chk was performed after modifications; sample garnet $35 \mu \mathrm{m}$ was performed upon procurement of the analyzer (note that the Undersize \% ordinate is shown; however for this graph, these curves were not plotted). 
Analyses were then performed on an actual radioactive tank farm sample-WM-182 Sample \#4. These results were quite consistent; they are presented in Figure 7. This verified that the modified Horiba LA-300 laser scattering PSD analyzer is operational for performing remote PSD analysis on radioactive slurries at the RAL facility.

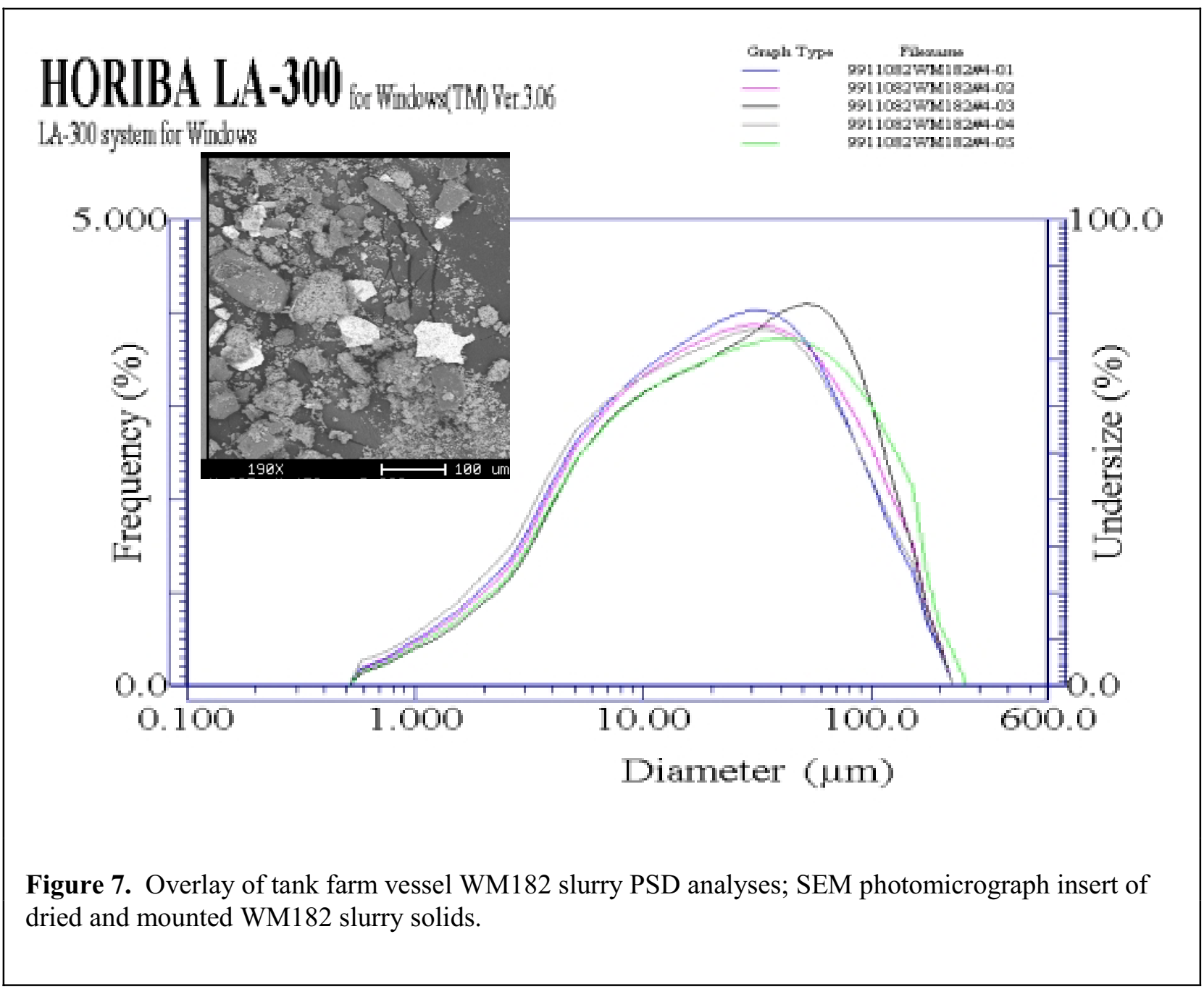

\section{CONCLUSIONS}

This method and deployment of this technology in a gamma radiation environment is in an exploratory stage. The risk of malfunction in this radiation environment is countered by the gaining of this tremendously useful fundamental engineering data. Successful acquisition of this data, in conjunction with other characterization analyses, provides important information that can be used in the myriad of potential radioactive waste management alternatives. 